\title{
Trends of Kalemia at Diagnosis of Acidosis versus Non-Acidosis Diabetic Ketosis Décompensations in Ouagadougou (Burkina Faso)
}

\author{
Oumar Guira1,2*, Hervé Tiéno ${ }^{1,2}$, Abraham Bagbila², Yempabou Sagna², \\ Gérard Coulibaly1,3, Lassané Zoungrana², Joseph Y. Drabo',2 \\ ${ }^{1}$ Unité de Formation et de Recherche en Sciences de la Santé, Université de Ouagadougou, \\ Ouagadougou, Burkina Faso \\ ${ }^{2}$ Service de Médecine Interne, Centre Hospitalier Universitaire Yalgado Ouédraogo, \\ Ouagadougou, Burkina Faso \\ ${ }^{3}$ Service de Néphrologie et d'Hémodialyse, Centre Hospitalier Universitaire Yalgado Ouédraogo, \\ Ouagadougou, Burkina Faso \\ Email: "oumgui@yahoo.fr
}

Received 17 January 2016; accepted 20 February 2016; published 23 February 2016

Copyright (C) 2016 by authors and Scientific Research Publishing Inc.

This work is licensed under the Creative Commons Attribution International License (CC BY). http://creativecommons.org/licenses/by/4.0/

(c) (i) Open Access

\section{Abstract}

Introduction: Electrolyte's profile in non-acidosis diabetic ketosis is poorly specified. We aimed to determine the nature of diabetic ketosis decompensations as well as the profile of kalemia and factors associated with its disorders at diagnosis of acidosis compared to non-acidosis diabetic ketosis. Methods: The study was retrospective from 1 January 2010 to 31 December 2011 in Yalgado Ouédraogo teaching hospital. Diabetic in-patients suffering from simple ketosis, keto-acidosis or mixed decompensation, who achieved blood electrolytes assessment before intensive insulin therapy were included. Results: Sixty two patients were studied. The sex ratio was 0.7 and the mean age was 41.7 years. Keto-acidosis, simple ketosis and mixed decompensation were diagnosed respectively in $18(29 \%), 32(51.6 \%)$ and $12(19.4 \%)$ patients. Kalemia was normal in 42 $(67.7 \%)$, while hypokalemia and hyperkalemia were reported respectively in $11(17.8 \%)$ and 9 $(14.5 \%)$ patients. Kalemia was often normal in all types of ketosis decompensation and disorders of kalemia occurred more in patients with keto-acidosis $(50 \%)$ than those with simple ketosis $(21.9 \%) ; p=0.04$. Renal failure was diagnosed in 10 patients $(50 \%)$ with and $2(4.8 \%)$ without kalemia's disorders; $p=0.0001$. Seven patients $(35 \%)$ with and $4(9.5 \%)$ without kalemia's disorders suffered from unconsciousness; $p=0.02$. It happens more in hyperkalemia $(44.4 \%)$ than in

"Corresponding author.

How to cite this paper: Guira, O., Tiéno, H., Bagbila, A., Sagna, Y., Coulibaly, G., Zoungrana, L. and Drabo, J.Y. (2016) Trends of Kalemia at Diagnosis of Acidosis versus Non-Acidosis Diabetic Ketosis Décompensations in Ouagadougou (Burkina Faso). Open Journal of Internal Medicine, 6, 1-5. http://dx.doi.org/10.4236/ojim.2016.61001 
normal kalemia condition $(9.5 \%) ; p=0.02$. Conclusion: If kalemia is often normal in all types of diabetic ketosis emergencies, hypokalemia is the most initial frequent potassium disorder.

\title{
Keywords
}

\author{
Diabetic Ketosis, Kalemia Disorders, Burkina Faso
}

\section{Introduction}

Hyperglycemic emergencies are acute life-threatening disorders [1]-[4]. Among these emergencies, diabetic ketoses are hyperglycemic states with an increase in ketogenesis (acetoacetate and beta-hydroxybutyrate) resulting from a severe deficiency of insulin and high levels of hormones that oppose the effects of insulin, particularly glucagon. Depending on the stage of diagnosis and the content in ketone bodies, diabetic ketosis initially consists of a simple ketosis, and in the lack of an adequate management, it leads to ketoacidosis and sometimes to clinical forms combining hyperosmolarity. These emergencies are common and pejorative in low-income countries because of social, economic and medical barriers to their prevention, their early diagnosis and their treatment. So, hyperglycemic emergencies are the leading cause of diabetic patients' hospitalization and diabetesrelated death in Nigeria [5]. The poor prognosis is partly correlated to various electrolytes disorders. Among these, potassium's disorders (occurring at diagnosis and/or during the intensive insulin therapy) are deleterious because of cardiac, neurogical and muscular dysfunctions they cause; these troubles are an obsession during the management of hyperglycemic emergencies. Potassium's disorders result from modifications in cellular exchanges and renal excretion of potassium in acid-base imbalance, severe insulin openia and renal failure conditions during these emergencies, as well as intensive insulin supply [6]-[9]. According to pathophysiological mechanisms, hyperkalemia is the common expected profile of kalemia at diagnosis of ketoacidosis. But, diabetic ketosis emergencies present phenotypes devoid of acidosis (simple diabetic ketosis decompensation). Studies don't address electrolytes disorders in these clinical forms increasingly reported in type 2 ketosis prone diabetes, a type 2 diabetes whose pathogenesis is nowadays unclear [10] [11]. Are electrolytes disorders similar to what are observed in keto-acidosis? We compared the profile of kalemia in different types of diabetic ketosis and investigated factors associated with its disorders. Findings could help to an efficient management of potassium's supplementation during the initial care of these metabolic emergencies, especially those without acidosis in Ouagadougou.

\section{Patients and Methods}

\subsection{Design of the Study}

The study was retrospective from 1 January 2010 to 31 December 2011 in the department of Internal Medicine, Yalgado Ouédraogo teaching hospital (CHUYO).

\subsection{Patient's Selection}

In-patients suffering from simple diabetic ketosis, keto-acidosis or mixed decompensation, who achieved blood electrolytes assessment before the beginning of intensive insulin therapy, were included. Those who reported treatments disturbing kalemia or a previous renal failure were not included.

\subsection{Patient's Evaluation}

We diagnosed simple ketosis as glycemia $\geq 13.5 \mathrm{mmol} / \mathrm{l}$, glucosuria $\geq+++$, ketonuria $\geq++$ and alkaline reserve $>15 \mathrm{mmol} / \mathrm{l}$; keto-acidosis as glycemia $\geq 13.5 \mathrm{mmol} / \mathrm{l}$, glucosuria $\geq+++$, ketonuria $\geq++$ and alkaline reserve $<15 \mathrm{mmol} / 1$ and mixed decompensation as keto-acidosis criteria + plasma osmolarity $>330 \mathrm{mOsm} / \mathrm{l}$. Hypokalemia or hyperkalemia were severe for values $\leq 2 \mathrm{mmol} / 1$ or $\geq 7 \mathrm{mmol} / \mathrm{l}$. Electrocardiogram was not available for any patient. Biochimical analyses were performed using an automatic biochemistry analyzer Architect c 4000 (Abbott) to dose glycemia, kalemia and alkaline reserve and Keto-Diastix reagent strips (Bayer) to measure glucosuria and ketonuria. 


\subsection{Ethical Considerations}

The institutional committee has approved the study. For this retrospective study, no nominative data were collected and data's confidentiality was monitored during the study.

\subsection{Statistical Considerations}

Data were collected from a questionnaire specifying the epidemiological characteristics of diabetes, phenotypes of ketosis decompensation, value of kalemia, factors associated with different level of kalemia. Analysis was by Fisher's tests to compare qualitative variables and Student's test to compare quantitative variables. A p value of less than 0.05 was significant.

\section{Results}

\subsection{Epidemiological Features of Diabetes}

Ninety patients were hospitalized with ketosis decompensation. Sixty two (68.9\%) fulfilled criteria for inclusion: 26 (41.9\%) males and 36 (58.1\%) females; sex ratio 0.7. Their mean age was $41.7 \pm 15.3$ years (limits: $11-80)$. Diabetes was newly diagnosed in $30(48.4 \%)$ patients. It was type 1 in 19 (30.6\%) and type 2 in $42(67.7 \%)$ patients.

\subsection{Phenotypes of Ketosis Decompensation}

Acidosis was reported in 30 (48.4\%) patients: 18 (29\%) keto-acidosis and 12 (19.4\%) mixed decompensation. Ketosis was simple in 32 (51.6\%). Glycemia on admission was $22.2 \pm 7$ mmol/l (limits: 14 and 49). Symptom's duration was $15 \pm 10$ days (limits: 2 and 38). Table 1 reports the demographic characteristics and the average glycemia of patients according to the phenotype of diabetic ketosis.

\subsection{Profile of Kalemia and Factors Associated with Its Disorders}

Kalemia was $4.3 \pm 1.1 \mathrm{mmol} / \mathrm{l}$ (limits: 1.7 and 7.8). It was normal in $42(67.7 \%)$, while hypokalemia was diagnosed in $11(17.8 \%)$ and hyperkalemia in $9(14.5 \%)$ patients. Hypokalemia and hyperkalemia were severe respectively in 4 and 5 patients. Disorders were common in keto-acidosis $(50 \%)$ than simple ketosis $(21.9 \%) ; \mathrm{p}=$ 0.04 . Table 2 reports the frequency of different levels of kalemia according to the nature of diabetic ketosis. Renal failure was diagnosed in 10 patients $(50 \%)$ with and $2(4.8 \%)$ without kalemia's disorder; $p=0.0001$. Table 3 reports the factors associated with different levels of kalemia. Unconsciousness occurred in 7 patients

Table 1. Demographic characteristics and average blood glucose in patients according to the phenotype of diabetic ketosis.

\begin{tabular}{cccc}
\hline & Keto-acidosis & Ketosis & Mixed value \\
\hline Mean age & $30.57 \pm 11.50$ & $44.93 \pm 14.89$ & $44.93 \pm 15.35$ \\
Sex-ratio & 0.27 & 0.77 & 1.28 \\
Mean glycemia & $27.92 \pm 4.99$ & $20.53 \pm 5.23$ & 0.001 \\
\hline
\end{tabular}

Table 2. Frequency of different levels of kalemia depending on the phenotype of diabetic ketosis.

\begin{tabular}{|c|c|c|c|c|}
\hline & $\mathrm{A}=$ Keto-acidosis & $\mathrm{B}=$ ketosis & $\mathrm{C}=$ Mixed & $\mathrm{p}$ \\
\hline \multirow{3}{*}{ Hyperkalemia } & \multirow{3}{*}{$4(22.2 \%)$} & \multirow{3}{*}{$2(6.2 \%)$} & \multirow{3}{*}{$3(25 \%)$} & $A-B=0.11$ \\
\hline & & & & $A-C=0.59$ \\
\hline & & & & $\mathrm{B}-\mathrm{C}=0.11$ \\
\hline \multirow{3}{*}{ Hypokalemia } & \multirow{3}{*}{$5(27.8 \%)$} & \multirow{3}{*}{$5(15.6 \%)$} & \multirow{3}{*}{$1(8.3 \%)$} & $\mathrm{A}-\mathrm{B}=0.25$ \\
\hline & & & & $\mathrm{A}-\mathrm{C}=0.20$ \\
\hline & & & & $B-C=0.47$ \\
\hline \multirow{3}{*}{ Normal kalemia } & \multirow{3}{*}{$9(50 \%)$} & \multirow{3}{*}{$25(78.2 \%)$} & \multirow{3}{*}{$8(66.7 \%)$} & $\mathrm{A}-\mathrm{B}=0.04$ \\
\hline & & & & $A-C=0.30$ \\
\hline & & & & $B-C=0.33$ \\
\hline
\end{tabular}


Table 3. Factors associated with different levels of kalemia in the initial phase of diabetes ketosis emergency.

\begin{tabular}{|ccccc|}
\hline & $\mathrm{D}=$ Hyperkalemia & $\mathrm{E}=$ Hypokalemia & $\mathrm{F}=$ Normal kalemia & $\mathrm{p}$ \\
\hline Digestive troubles & & & $12(28.6)$ & $\mathrm{D}-\mathrm{F}=0.53$ \\
\hline Yes & $4(44.4)$ & $4(36.4)$ & $30(71.4)$ & $\mathrm{E}-\mathrm{F}=0.43$ \\
No & $5(55.6)$ & $7(63.6)$ & & $\mathrm{D}-\mathrm{E}=0.50$ \\
\hline Dehydratation & & $10(23.8)$ & $\mathrm{D}-\mathrm{F}=0.19$ \\
Yes & $4(44.4)$ & $6(54.5)$ & $32(76.2)$ & $\mathrm{E}-\mathrm{F}=0.05$ \\
No & $5(55.6)$ & $5(45.5)$ & & $\mathrm{D}-\mathrm{E}=0.03$ \\
\hline Renal failure & & $2(4.8)$ & $\mathrm{D}-\mathrm{F}=0.00$ \\
Yes & $7(77.8)$ & $2(22.2)$ & $40(95.2)$ & $\mathrm{E}-\mathrm{F}=0.05$ \\
\hline No & $2(22.2)$ & $8(72.7)$ & &
\end{tabular}

$(35 \%)$ with and $4(9.5 \%)$ without disorder; $\mathrm{p}=0.02$. It was more frequent in hyperkalemia $(44.4 \%)$ than normal kalemia $(9.5 \%) ; \mathrm{p}=0.02$. One death occurred, related to an infectious shock.

\section{Discussion}

Simple ketosis was the most frequent ketosis emergencies phenotype (51.6\%). Disorders of kalemia were initially diagnosed in $32.3 \%$ patients and were associated with renal failure. Our findings are subject to a selection bias relevant to the non-inclusion of a third of patients who didn't achieve electrolytes assessment. Simple ketosis often corresponded to type 2 ketosis prone diabetes, confirming the significance of this type of diabetes in black Africans [10] [11]. The frequency of mixed ketosis emergencies (19.4\%) was less than the $30 \%$ and $33 \%$ reported respectively in Australia (30\%) and Rhode Island (33\%) [1] [12], partly, because of differences in the calculation of plasma osmolarity and the definition of hyperosmolarity [3] [12].

The average kalemia, i.e. $4.3 \mathrm{mmol} / \mathrm{l}$ was lower than findings in an U.S. study, i.e. $5.55 \mathrm{mmol} / \mathrm{l}$ in males and $5.03 \mathrm{mmol} / \mathrm{l}$ in females [8]. In our study, kalemia was often normal in the initial phase of all types of diabetic ketosis, especially in simple ketosis. Otherwise, hypokalemia was the common abnormality (17.8\%). Authors report this disorder in ketosis emergencies with a frequency ranged from $5.6 \%$ to $47 \%$ [2] [13] [14], and kalemia sometimes can collapse below $2 \mathrm{mmol} / \mathrm{l}$ [13]. Because low normal or normal kalemia during these emergencies result in an absolute depletion of potassium, the risk of iatrogenic hypokalemia prompt to delay the onset of intensive insulin therapy as long as potassium is below $3.3 \mathrm{mmol} / 1$ [4] [15]. Given this, recommendations to empirically defer when kalemia's monitoring is unavailable supplements in potassium at least two hours after starting intensive insulin therapy can be harmful for the majority of our patients with normal or low blood potassium. Thus, assessment of kalemia is essential to an efficient and safety management in hyperglycemic emergencies.

At diagnosis, hyperkalemia was unusual in ketosis emergencies and wasn't more frequent in acidosis compared to non-acidosis conditions. This implies for its pathogenesis other mechanisms than acidosis: the role of ketone bodies was discussed, but to date is recalled in favor of major insulinopenia and renal failure [7]. The relation between hyperkalemia and renal failure appears in our study, hyperkalemia resulting certainly from decrease in renal potassium loss and renal acidosis [2] [7] [8]. Moreover, hyperkalemia is classically expected in keto-acidosis [4] [8]. This observation was not common in our patients (22.2\%) and in Nigerian's patients (2.1\%) [2], compared to $32 \%$ reported by Van Gal [9]. In developing countries, medical care is often tardy and hyperkalemia can be canceled because of significant urinary potassium loss secondary to massive glucosuria. In our observation, unconsciousness was rather common in hyperkalemia. Renal failure could through uremic encephalopathy be a promoting factor of these neurological anomalies in patients. Cerebral dysfunction consecutive to hypokalemia has been described in a diabetic patient [16].

\section{Conclusion}

Potassium's disorders could occur in all type of diabetic ketosis emergencies. But, despite expectations, kalemia is often normal, otherwise hypokalemia is the most frequent disorder in simple ketosis and keto-acidosis emergencies in our patients. Initial empiric management of potassium supplementation without kalemia's status ac- 
cording to some recommendations can be deleterious in these circumstances. This justifies the necessity of electrolytes assessment for a successful and safety management of hyperglycemic emergencies. Prevention of these diabetic emergencies by improving access to diabetes care and strengthening the therapeutic education must be the final goal, particularly in low-income countries where their management is difficult.

\section{Conflict of Interests}

The authors declare no conflict of interest in relation to the subject.

\section{References}

[1] MacIsaac, R.J., Lee, L.Y., McNeil, K.J., Tsalamandris, C. and Jerums, G. (2002) Influence of Age on the Presentation and Outcome of Acidotic and Hyperosmolar Diabetic Emergencies. Internal Medicine Journal, 32, 379-385. http://dx.doi.org/10.1046/j.1445-5994.2002.00255.x

[2] Ogbera, A.O., Awobusuyi, J., Unachukwu, C. and Fasanmade, O. (2009) Clinical Features, Predictive Factors and Outcome of Hyperglycaemic Emergencies in a Developing Country. BMC Endocrine Disorders, 9, 9. http://dx.doi.org/10.1186/1472-6823-9-9

[3] Savaş-Erdeve, Ş., Berberoğlu, M., Oygar, P., Şıklar, Z., Kendirli, T., Hacıhamdioğlu, B., Bilir, P. and Öçal, G. (2011) Efficiency of Fluid Treatments with Different Sodium Concentration in Children with Type 1 Diabetic Ketoacidosis. Journal of Clinical Research in Pediatric Endocrinology, 3, 149-153.

[4] Kitabchi, A.E., Umpierrez, G.E., Miles, J.M. and Fisher, J.N. (2009) Hyperglycemic Crises in Adult Patients with Diabetes. Diabetes Care, 32, 1335-1343. http://dx.doi.org/10.2337/dc09-9032

[5] Chinenye, S. and Young, E. (2011) State of Diabetes Care in Nigeria: A Review. The Nigerian Health Journal, 11, 101-106.

[6] Sotirakopoulos, N., Kalogiannidou, I., Tersi, M., Armentzioiou, K., Sivridis, D. and Mavromatidis, K. (2012) AcidBase and Electrolyte Disorders in Patients with Diabetes Mellitus. Saudi Journal of Kidney Diseases and Transplantation, 23, 58-62.

[7] Adrogué, H.J., Lederer, E.D., Suki, W.N. and Eknoyan, G. (1986) Determinants of Plasma Potassium Levels in Diabetic Ketoacidosis. Medicine (Baltimore), 65, 163-172. http://dx.doi.org/10.1097/00005792-198605000-00004

[8] Fulop, M. (1990) Hyperkalemia in Diabetic Ketoacidosis. The American Journal of the Medical Sciences, 299, 164169. http://dx.doi.org/10.1097/00000441-199003000-00004

[9] Van Gaal, L.F., De Leeuw, I.H. and Bekaert, J.L. (1986) Diabetic Ketoacidosis-Induced Hyperkalemia. Prevalence and Possible Origin. Intensive Care Medicine, 12, 416-418. http://dx.doi.org/10.1007/BF00254673

[10] Mauvais-Jarvis, F., Sobngwi, E., Porcher, R., Riveline, J.P., Kevorkian, J.P., Vaisse, C., Charpentier, G., Guillausseau, P.J., Vexiau, P. and Gautier, J.F. (2004) Ketosis-Prone Type 2 Diabetes in Patients of Sub-Saharan African Origin: Clinical Pathophysiology and Natural History of $\beta$-Cell Dysfunction and Insulin Resistance. Diabetes, 53, 645-653. http://dx.doi.org/10.2337/diabetes.53.3.645

[11] Monabeka, H.G. and Nsakala-Kibangou, N. (2001) Coma céto-acidosique inaugurant le diabète chez l'adulte noir. Cahiers d'études et de Recherches Francophones/Santé, 11, 127-129.

[12] Wachtel, T.J., Tetu-Mouradjian, L.M., Goldman, D.L., Ellis, S.E. and O’Sullivan, P.S. (1991) Hyperosmolarity and Acidosis in Diabetes Mellitus: A Three-Year Experience in Rhode Island. Journal of General Internal Medicine, 6 , 495-502. http://dx.doi.org/10.1007/BF02598216

[13] Sarr, A., Diedhiou, D., Ndour-Mbaye, N., Leye, Y., Ka-Cisse, M., Leye, A. and Diop, S. (2011) Ketoacidosis in Type 1 Diabetes Mellitus: About 73 Cases in Dakar. Mali Medical, 26, 50-54.

[14] Arora, S., Cheng, D., Wyler, B. and Menchine, M. (2012) Prevalence of Hypokalemia in ED Patients with Diabetic Ketoacidosis. The American Journal of Emergency Medicine, 30, 481-484. http://dx.doi.org/10.1016/j.ajem.2011.01.002

[15] Murthy, K., Harrington, J.T. and Siegel, R.D. (2005) Profound Hypokalemia in Diabetic Ketoacidosis: A Therapeutic Challenge. Endocrine Practice, 11, 331-334. http://dx.doi.org/10.4158/EP.11.5.331

[16] Shintani, M., Yamashita, M., Nakano, A., Aotani, D., Maeda, K., Yamamoto, T. and Nishimura, H. (2005) Central Pontine and Extrapontine Myelinolysis Associated with Type 2 Diabetic Patient with Hypokalemia. Diabetes Research and Clinical Practice, 68, 75-80. http://dx.doi.org/10.1016/j.diabres.2004.08.005 